Article

\title{
Spiritual Exemplars: An Introduction
}

\section{W. George Scarlett}

Eliot-Pearson Department of Child Development, Tufts University, Medford, MA 02155, USA; E-Mail: george.scarlett@ tufts.edu

Received: 12 March 2012; in revised form: 27 March 2012 / Accepted: 31 March 2012 /

Published: 10 April 2012

\begin{abstract}
This essay introduces the special issue, provides criteria for evaluating spiritual exemplars, presents a case study to illustrate how spiritual exemplars can extend our knowledge of spiritual development, and makes important distinctions between types of exemplars and between positive and pathological spirituality.
\end{abstract}

Keywords: spiritual exemplars; criteria for evaluating; spiritual development; noble purpose; patterns of faith; spiritual pathology

\section{Spiritual Exemplars: Understanding and Inspiration}

This special edition explains the spiritual lives of famous exemplars, both to shed light on the nature of spirituality and its development and to inspire readers to refine and develop their own faith so that they can better enhance the quality of the world. The lives of spiritual exemplars give us embodied spirituality and provide us with essential criteria and clues for evaluating and explaining spiritual development. Most important, they show us the powerful role faith can play in motivating and sustaining effort in the service of noble purpose.

\section{Criteria for Evaluating}

Whether or not an individual qualifies as a spiritual exemplar is, of course, open to interpretation. However, the fact that spiritual exemplars have universal appeal suggests there are generally held, tacit criteria for evaluating. I suggest six in particular, namely, goodness, noble purpose, success, integrating faith and reason, respect for diversity, and strong positive faith.

The first criterion is the most obvious, namely, that spiritual exemplars are good. They are good in the ways they treat others (with respect, compassion, care, etc.), and they are good in the ways they 
dedicate their lives, often at much sacrifice to their own comfort and safety, to their causes (feeding the poor, fighting racism, etc.). Furthermore, they are good not just in the sense that they do good; they are good also in the sense that they are wise and strong in character-with wisdom and character seen most strikingly in their being both deeply connected to life's problems and tragedies and at the same time not consumed by problems and tragedies. For example, Abraham Lincoln lost two sons, one while he was president (from drinking bad White House water), and Nelson Mandela was imprisoned for twenty-seven years. However, despite their tragedies and suffering, both kept their spirit, indeed matured and were strengthened by their tragedies and suffering - as is true of spiritual exemplars in general.

Character refers to virtues. Wisdom and persistence in the face of adversity are only two virtues among many. What is striking about spiritual exemplars is not simply that they have virtues but also that they show a balance between "hard" and "soft" virtues. Hard virtues are those emphasized in war, on the playing field, and in all situations calling for toughness. They include courage, dedication, and persistence. Soft virtues are those emphasized in connecting to others. They include honesty, humility, and especially compassion. Each of the positive exemplars discussed in this special edition have demonstrated character in ways both "hard" and "soft" - as when Lincoln showed steadfastness in the face of opposition from political rivals while showing compassion for wounded prisoners of war.

Goodness is also the focus of a second agreed upon criterion-namely, the goodness of a spiritual exemplar's purpose. Muir's purpose was to protect wilderness. Lincoln's purpose was to preserve the union and abolish slavery. The rest of the spiritual exemplars discussed in this special issue and spiritual exemplars in general all have taken up noble purpose. Their contemporaries may not have fully appreciated their purposes, but we realize and appreciate them now, and we understand how their lives were ennobled by their taking up noble purposes as their life's mission.

A third criterion for discerning spiritual exemplars is the criterion of success. Those we point to as being spiritual exemplars are apt to have accomplished a great deal and been successful in their missions and in moving others to follow their lead. Would Lincoln be so revered as a spiritual exemplar had the South won the Civil War? Would Muir have become an icon of spirituality had he failed to preserve the wilderness? Would any of those widely recognized as spiritual exemplars been widely recognized had they not used their considerable knowledge and skills so as to succeed? Not likely.

A fourth criterion has to do with the ongoing struggle to integrate faith and reason - to remain at once faithful to the sacred and what cannot be measured while also remaining intellectually responsible. Muir used his scientific study of Yosemite Valley to heighten our appreciation of its value to humankind; Lincoln argued with religiously minded dogmatists that these are not the days of miracles (and so we must rely on reason); Mandela put his faith in lawyerly arguments to win over his adversaries to his vision of a just community; even Atticus Haygood and Mother Teresa, both evangelical in their own way, appealed to reason as they deduced from their strong image of a loving Christ that each and every one of us should love the same.

Spiritual exemplars meet a fifth criterion as they show remarkable capacity to develop strong convictions while also showing respect, even love, for those quite different from themselves. Since the Age of Discovery when so many different faith traditions came face to face with one another, there has been this dilemma of how to maintain and develop one's own particular faith while understanding and 
respecting those having quite different patterns of faith. Obviously, for a great many, there has been no felt dilemma, since, a great many have either ignored others from different traditions or taken up the cause of converting them in a way that makes clear they thought others were inferior (or worse). But more and more, ignoring or trying to convert others deemed inferior seems inappropriate and certainly not the ideal. More and more, having strong faith while understanding and caring for others as fellow human beings no less worthy despite their differences is felt to be the only caring option. At the very least, one can cultivate a sense of wonder and appreciation for the diverse ways that humans express their religiosity and spirituality.

Each of the positive exemplars to be discussed shows us how we can have strong faith while still understanding and respecting others - even when others have patterns of faith quite different from our own. Lincoln may have said it best when responding to questions about the presence of so many religious denominations. He said, "They are all getting someone in that the others could not." And with his mission to "save" others, Atticus Haygood could still connect and respect others who had quite different faith patterns or no faith pattern at all - in part because his image of Christ was that of the "man for others" and in part because his vision of community was egalitarian in nature.

When these five criteria just mentioned are made explicit, most accept them as criteria for discerning spiritual exemplars. But I add a sixth, less agreed upon, criterion, and privilege it as the motor explaining why and how spiritual exemplars become so good, wise, successful, and capable of maintaining convictions while being intellectually honest and tolerant, even loving, toward diverse groups. This sixth criterion points to the fact that spiritual exemplars have strong positive faith.

Strong positive faith is a far more controversial criterion than the previous four because faith is so often confused with belief and institutional practices. A belief-institution way of defining faith is unfortunate because it robs the concept of its power to capture the experience of the faithful. As experienced by the faithful themselves, faith is who they are, what they live for, how they orient themselves in the world. As such, faith explains why they persevere even in the face of death and seeming overwhelming odds. This point is essentially the same as that taken in research on moral exemplars [1].

Furthermore, much of the time their faith is expressed not in beliefs and institutional practices but in the very acts for which they are famous: such as feeding the poor (Mother Teresa), fasting to help restore peace (Gandhi), and crafting a chair so well that an angel passing by might wish to sit on it (the Shakers). Throughout this special edition, we will find that spiritual exemplars are those who have extraordinary faith, faith strong enough to figuratively 'move mountains' and impact history.

Spiritual exemplars are great, then, not so much for their beliefs as for their faith that energized their actions, kept them steadfast in the face of adversity, and in the end, proved the deciding factor in their success. Lincoln during his presidency cannot be separated from his faith in a mysterious, yet just and caring God nor from his faith in the great principle of equality expressed in the American Declaration of Independence. Mother Teresa during her later years serving the desperately poor cannot be separated from her extraordinary faith in and identification with Jesus on the cross. John Muir cannot be separated from his faith in a God who made the mountains ("God's cathedrals."). In short, these and other spiritual exemplars show us that faith can develop in persons and communities to the point where their faith becomes who they are. When this happens, we see just how faith can move, if not mountains, then at least history. 
This special edition explains how spiritual exemplars exhibit different patterns of faith from one another. The fact that there are differences in patterns mirrors other observations of exceptionality. For example, Howard Gardner in his book Creating Minds [2] shows that creativity takes quite different patterns as one goes from one domain to another, for example, from science to art.

With respect to spiritual development and spiritual exemplars, the first difference in pattern is between working for justice and showing care. While all positive exemplars work for justice and show care, each may be known for one more than the other. Lincoln became legend for his showing care for Union deserters and the Confederate wounded, but his place in history was earned by his life-long battle against the injustice of slavery. Mother Teresa's work with the destitute of Calcutta righted an injustice done to the destitute, but her place in history was earned by her showing extraordinary care for the poor and for all those who suffer in isolation. Lincoln in Calcutta would likely have sought political solutions to create a more just Indian society, one offering greater opportunities for the poor and those victimized by the caste system. Mother Teresa in Washington D.C. at the time of the Civil War would likely have been by the bedsides of the wounded.

Exemplars' pattern of faith differs from one another also because faith is culturally and contextually situated and because faith is a response to particular challenges. Lincoln's faith was inextricably bound up with the American dream of building a democratic community, with the fight against slavery, and with the trend at that time toward integrating Calvinistic thinking with the thinking of early $19^{\text {th }}$ century American Transcendentalists. In contrast, Mother Teresa's faith developed from her traditional Catholic upbringing, from struggles following her father's death, and, in her later years, from her feeling abandoned by or at least cut off from communicating with God. As such, it focused on themes of sacrifice, devotion, and Christ's experience of abandonment on the cross.

Patterns of faith also differ from one another according to whether individuals adopt a theocentric or non-theocentric perspective. Mother Teresa and Atticus Haygood are examples of exemplars adopting a strong theocentric perspective on life in general — as is evident in Mother Teresa's ongoing preoccupation with "God's will" and Atticus Haygood's ongoing preoccupation with "saving" and "being saved". Nelson Mandela is an example of an exemplar adopting a mostly non-theocentric perspective - as is evident in his ongoing work of appealing in rationale and respectful ways to humans' capacity for grasping what is just and for creating a harmonious community.

Implicit in this approach is an understanding that exemplars are not simply or even mainly to be defined in terms of their religious traditions. Lincoln, Mother Teresa, John Muir, Nelson Mandela, Atticus Haygood, all five can justifiably be called Christians, meaning they were baptized and raised as Christians. However, the differences between them both in the content and patterns of their faith attest to the fact that the category, Christian, is not very useful for describing the specific ways that they showed themselves to be spiritual exemplars. Lincoln's pattern was defined by his integrating traditional Calvinistic conceptions of God with early $19^{\text {th }}$ century Transcendentalist thinking about the sacred. Mother Teresa provides a classic pattern among Roman Catholics prior to Vatican II and the liberalization of the Catholic Church in the 1960's, but later on, her faith grew into something quite different than what we normally take to be conventional or classic. John Muir provides a pattern that uses Christian terms to describe his experience of the natural world, but it is also a pattern found in ancient Taoism. And Nelson Mandela's pattern provides a Christian's valuing of forgiveness, a humanist's faith in reason, and a traditional South African tribesman's faith in harmonious community, 
to understand spiritual exemplars we must operate at a more personal and specific level by showing the special nature of their patterns of faith.

The same is true of geographical region. The sample here is not evenly distributed among different geographical regions and different cultures. And yet, because spiritual exemplars speak to what is universal, we can learn much from even a small sample. My hope is that readers will use the articles in this special edition as a useful way to understand spiritual exemplars and their importance - and then go on to seek out discussions of exemplars from every region and every culture because the meaning of the six criteria for evaluating shifts as one goes from one faith tradition or culture to another, even as positive spiritual exemplars everywhere speak to what is universal.

\section{Spiritual Development: The Case of Mother Teresa}

How should we explain the development of spiritual exemplars - and, by extension, spiritual development in general? Besides inspiring us to do better and be better persons, spiritual exemplars also show us how we might best explain spiritual development. Obviously, the stories of their development differ from one another, and the pathways each followed or follows are unique to themselves. However, there are general insights that can be inferred from studying their development and pathways - in particular, the general insight that development refers to the ways that systems (biological, cognitive, contextual, and other systems) dynamically interact with one another and, under pressure or with the aid of triggers, produce transformations in the overall pattern of interacting systems [3]. To illustrate, consider the development of Mother Teresa.

Mother Teresa is universally recognized as a religious and spiritual exemplar - as indicated by her receiving a Nobel prize for her work with the poor but also as indicated by her being a European Catholic nun given a state funeral in a mostly Hindu country, India. Mother Teresa developed a powerful faith whose pattern both fits within the Catholic faith tradition and at the same time shows unique and uncommon features.

The life of Mother Teresa illustrates just how developmental systems thinking can help explain otherwise puzzling phenomena related to her spiritual development. How did it come about that already, at age 12, she had developed the long-term purpose of devoting her life to God? By what processes did she try to discern God's will when trying to decide, at age 18 , whether to become a nun and at age 36, when deciding to leave the convent and devote herself entirely to serving the poor? Most perplexing, how did it happen that throughout her decades of heroic work with the poor, she suffered from chronic doubt and feelings of abandonment by God?

The first question takes us to the circumstances surrounding the upbringing of Mother Teresa, then Agnes Bojaxhiu. In 1910, Agnes was born to a well-to-do family in Skopja, Yugoslavia. Skopja had a mostly Muslim population. The Bojaxhiu family belonged to a small, close-knit community of Albanian Catholics who used their parish both for religious purposes and to preserve their culture. Within the family, religion was a daily presence. Each morning, the children were taken to Mass, and at night, the family prayed together. Furthermore, Agnes's extremely religious mother, Drana, regularly took the children to help her distribute food and money to the local poor. When she was 9, her father, then a city counselor active in a movement to have Skopje annexed to Albania, died. The strong suspicion was that he was poisoned by communist authorities opposed to his politics. At 12 , she 
listened to Jesuit missionaries visiting her church tell about their work in India, and this, she said, elicited in her a strong desire to become a missionary and dedicate her life to God.

Using developmental systems thinking, a number of observations can be made that bring out the significance of these facts and that suggest a way to explain Mother Teresa's precocious interest in dedicating her life to God. There is, first of all, the obvious, namely, that her precocity and the nature of her long-term purpose had to do with her coming from an extremely religious family and community - so that she was socialized, early on, to think and act as a religious person. However, so too were her siblings and so too are millions of children from highly religious families and communities, and yet very few show the same desire, at 12, to dedicate their lives to God. To use these facts in a more powerful way, we need to view them together as suggesting that something unusual, powerful, and complex was going on in the time leading up to Agnes's adopting this long-term, purely religious purpose. We begin with what is the most extraordinary fact mentioned, namely, the death of Agnes's father when she was 9 years old.

Compared to the general population, eminent historical figures are about three times more likely to suffer the death of a parent in childhood [4-6]. One reason given is that death of a parent creates insecurity and hardship that, if mastered, can leave an individual better equipped and more motivated to take on some long-term purpose and stick to it.

Based on the facts we know, such as her family struggling financially following the death of her father and about her mother keeping the family a devout Catholic family, we can assume that the death of her father triggered in young Agnes a heightened sense of vulnerability (insecurity) and dependence on God. It is not too much of a stretch, then, to imagine Agnes using her faith to master her insecurities by adopting the well-researched tactic of gaining control by giving up control to God [7]. In short, we can assume that the death of her father set in motion cognitive and affective processes that led to her gaining control by adopting the long-term purpose of giving up control and dedicating her life to God.

Evidence for this interpretation comes from the many instances throughout her life when Mother Teresa linked dedication to God with placing control entirely in his hands-as when she left the convent to serve the poor without a detailed plan and later on when she refused to fund-raise for the "Missionaries of Charity," the organization she founded to aid the poor. "Money," she said, "I never think of it. It always comes. The Lord sends it. We do his work. He provides the means. If he does not give us the means, that shows that he does not want the work. So why worry?" [8].

Ceding control to God and following His will requires that one discerns God's will, and so another life-long characteristic of Mother Teresa's faith was her constant puzzling to discern God's will. This was particularly evident around the time when she decided to become a nun. According to her own account [8], she asked her confessor, "How can I know if God is calling me and for what he is calling me?" and he replied, "If you are happy with the idea that God calls you to serve him and your neighbor, this will be proof of your vocation." Later on, she reported that while "praying... and singing in my heart, full of joy inside, when I took the life decision to wholly devote myself to God through religious life." This was one of several incidents where, early in her religious career, she used her positive feelings to assess God's will and sustain her faith and purpose.

The situation was quite different at age 36, when she was contemplating leaving the relative security of the convent to go out into the streets to serve the poor. At this time, and while on a train to Darjeeling, she experienced a direct call to leave the convent and serve the poor. She would have other 
such experiences, but during the next two years leading up to her gaining permission from her superiors to leave the convent, she felt abandoned by God. In one of her confessions at this time, she wrote [9]:

"I am told God loves me - and yet the reality of darkness and coldness and emptiness is so great that nothing touches my soul. Did I make a mistake in surrendering blindly to the Call of the Sacred Heart?" (p. 171).

Paradoxically, this feeling of spiritual abandonment became the basis for a new, more profound pattern of faith, one that emerged in the course of her work with the poor. Aided by the suggestion of one of her spiritual mentors, Mother Teresa was able to shift from using her positive feelings as guides to ascertain God's will and instead use her work with the poor as her only guide. Furthermore, she reframed her feeling of being abandoned as her experiencing the abandonment Christ felt on the Cross. By so doing, she transformed what normally is thought to be an experience that undermines faith into one that supported a powerful and strangely pure pattern of faith, one characterized by absolute dependence on God, a faith unmoored from the usual supports for faith, namely, happiness and security, as happiness and security are normally defined. This radical form of faith powered her work with the poor who became, for her, "Christ in his terrible disguise."

Again, I give this example to show how spiritual development can follow pathways not captured by belief-institution ways of explaining. For any given individual, we need to explain how triggers, processes, and systems combine to give that individual's development its own special character. I also give this example to demonstrate why, in order to explain spiritual development, we need to explain the emergence of new patterns of faith.

\section{Spiritual Pathology}

The last article in this special edition introduces readers to the concept of spiritual pathology or faith gone awry - and explains how our understanding of and appreciation for positive spiritual exemplars and positive spiritual development can be enhanced by our understanding negative exemplars whose faith has led to acts of destruction and evil. Here, the focus is on Adolf Hitler, one of history's clearest examples of pathological-destructive faith or faith gone awry. In this article, we see how faith can empower and move individuals and communities to do extraordinary evil.

The effort here is to show that evil and horrific acts carried out for spiritual reasons cannot be reduced to mental illness, criminal minds, historical conditions, or other variables that make no mention of problematic faith or faith gone awry. The hope is that this discussion will help explain evil and horrific acts by shedding light on how faith can go awry, how the images and content that make up a faith pattern can become corrupted - to the point of supporting the opposite of justice and care.

\section{Concluding Remarks}

This special edition is meant as an appetizer to whet the appetite for life-long study and appreciation of spiritual exemplars. As such, it is meant to be an introduction. However, I hope this collection of articles makes crystal clear how spiritual exemplars can serve as our life coaches - for the ways they show us how to be good and do good, but also for the ways they show us how to be faithful. 


\section{Acknowledgements}

This introduction and indeed this entire project is a long time in the making and owes particular gratitude to a number of very special scholars, in particular, Richard M. Lerner, Howard Gardner, Bill Damon, and Helmut Reich.

\section{References}

1. Colby, A.; Damon, W. Some Do Care: Contemporary Lives of Moral Commitment; Free Press: New York, NY, USA, 1992.

2. Gardner, H. Creating Minds: An Anatomoy of Creativity Seen Through the Lives of Freud, Einstein, Picasso, Stravinsky, Eliot, Graham, and Gandhi; Basic Books: New York, NY, USA, 1993.

3. Lerner, R.M. Developmental science, developmental systems, and contemporary theories of human development. In Handbook of Child Psychology: Theoretical Models of Human Development, 6th ed.; Lerner, R.M., Ed.; John Wiley \& Sons: Hoboken, NJ, USA, 2006; Volume 1.

4. Eisenstadt, J.M. Parental loss and genius. Am. Psychol. 1978, 33, 211-223.

5. Simonton, D.K. Greatness: Who Makes History and Why; Guilford: New York, NY, USA, 1994.

6. Sulloway, F. Born to Rebel; Pantheon: New York, NY, USA, 1996.

7. Baugh, J.R. Gaining control by giving up control: Strategies for coping with powerlessness. In Behavior Therapy and Religion; Miller, I.W.R., Martin, J.E., Eds.; Sage Publications: Newbury Park, CA, USA, 1988; pp. 125-138.

8. Teresa, M. My Life for the Poor: Mother Teresa of Calcutta; Harper \& Row: San Francisco, CA, USA, 1985.

9. Kolodiejchuk, B. Mother Teresa: Come by My Light-The Private Writings of the Saint of Calcutta; Doubleday: New York, NY, USA, 2007.

(C) 2012 by the author; licensee MDPI, Basel, Switzerland. This article is an open access article distributed under the terms and conditions of the Creative Commons Attribution license (http://creativecommons.org/licenses/by/3.0/). 